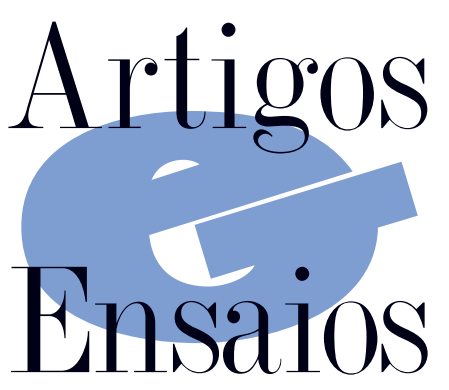

\section{INTERNACIONALIZAÇÃO E TENSÕES DA CIÊNCIA LATINO-AMERICANA}

\section{Pablo Kreimer}

INTRODUÇÃo A internacionalização é uma dimensão que está presente desde as origens da pesquisa em países latino-americanos: a institucionalização e o desenvolvimento de campos científicos "modernos" - em especial até o final do século XIX e início do XX - estiveram estreitamente vinculados com as relações entre pesquisadores locais e os "líderes" de cada disciplina na Europa, quer nas visitas de "viajantes" à América Latina, ou nas estadias de latinoamericanos no exterior. Isso corresponde a uma primeira fase, que podemos denominar de "internacionalização fundadora".

Uma vez que as disciplinas foram estabelecidas em instituições locais, a natureza das relações entre pesquisadores se alterou: a definição das agendas de pesquisa e as inovações conceituais entram em jogo dentro de uma tensão "localinternacional". Isso corresponde, portanto, a uma segunda fase, que podemos chamar de "internacionalização liberal" (1). Após o fim da Segunda Guerra Mundial, enquanto se estabeleciam, na maioria dos países desenvolvidos, as políticas científicas e tecnológicas - e se institucionalizaram, consequentemente, os protocolos de cooperação em matéria de ciência e tecnologia - os laços internacionais tornaram-se mais "formais" e mais "institucionalizados"; foi a fase de internacionalização "liberal-orientada" (2). Durante o último quarto do século XX, essas relações se modificaram de um modo mais radical: se durante as etapas precedentes as negociações entre pesquisadores do "centro" e da "periferia" deixavam aos últimos uma pequena margem de manobra, agora se pode observar uma tendência de relações de colaboração tomando a forma de um "contrato fechado", do tipo "pegar ou largar". É uma etapa marcada pela emergência de mega-redes (que podem incorporar em seu interior até 500 pesquisadores) e de amplas "regiões de pesquisa". Uma nova dinâmica torna-se, então, visível entre grupos hegemônicos e os de contextos periféricos. Poderíamos observar ali um paradoxo: os pesquisadores de elite dos países "não hegemônicos" são crescentemente convidados a participar de consórcios internacionais, mas suas condições de acesso são cada vez mais restritas e as margens de negociação tendem a ser mínimas.

O objetivo deste texto é o de aportar alguns elementos para a compreensão da última etapa, para o que analisaremos, nos parágrafos que seguem, algumas questões emergentes dos períodos anteriores para, em seguida, tentarmos caracterizar os desafios atuais para a ciência latino-americana.

\section{A INTEGRAÇÃO SUBORDINADA NA INTERNACIONALIZAÇÃO}

LIBERAL As comunidades científicas dos países latino-americanos (como em toda parte) não são espaços homogêneos de produção de conhecimento. Ao contrário, são organizações altamente segmentadas e em permanente tensão. Entre outras características, pode-se observar pesquisadores efetivamente integrados, que participam de programas de pesquisa internacionais, frequentam congressos regularmente, administram dados que os permitem orientar suas pesquisas para esta ou aquela direção e muitas vezes recebem subsídios de fontes internacionais. Por outro lado, há grupos e pesquisadores mal integrados, cujo grau de in- 


\section{Artigos \& Ensaios}

ternacionalização é deficiente - ou nulo - e que trabalham de modo isolado, por vezes orientados a necessidades locais, e que tentam frequentemente imitar as agendas de pesquisa dos grupos mais integrados (3).

Para além dessa descrição esquemática, é evidente que os grupos mais integrados nas redes internacionais muitas vezes são também os mais prestigiados nas instituições locais. Eles têm o poder de determinar a orientação, tanto no plano institucional - as políticas - como nas intervenções informais que influenciam as agendas, as linhas de pesquisa prioritárias e os métodos mais apropriados. Há, para esses investigadores, um círculo virtuoso: seu prestígio local de "base" Ihes permite estabelecer vínculos com seus colegas de centros de pesquisa internacional e, portanto, a participação em redes mundiais (e o reconhecimento externo) faz crescer de modo decisivo seu prestígio - e poder - local. Como resultado desse tipo de relação, os grupos mais integrados tendem a desenvolver atividades rotineiras: controles, provas, testes, de conhecimentos que já foram bem estabelecidos pelas equipes que assumem a coordenação nas redes internacionais (3). Isso traz uma implicação importante para a "ciência periférica": a definição das agendas de pesquisa é feita muitas vezes no seio dos grupos centrais e é logo adotada pelas equipes satélites, como uma condição necessária a uma integração de tipo complementar. Mas essas agendas respondem, em geral, aos interesses sociais, cognitivos e econômicos dos grupos e instituições dominantes nos países mais desenvolvidos.

Na longa fase de internacionalização liberal as possibilidades de negociação são muito restritas, mas os cientistas latino-americanos conservaram uma pequena margem de manobra que Ihes permitia influir sobre as agendas de colaboração com seus colegas de centros de maior prestígio, intervir sobre os métodos e os objetos de pesquisa escolhidos. A modalidade mais extendida pode ser sintetizada como segue:

Um jovem pesquisador latino-americano passa certo tempo em um laboratório do "centro" (graças a contatos já estabelecidos por seus predecessores). Nesse centro, especializa-se, por exemplo, no domínio de uma técnica escolhida por consenso entre os líderes de cada grupo, e sobre um objeto (por exemplo, uma proteína que tenha uma característica específica). Quando retorna a seu país de origem, em geral continua trabalhando sobre o mesmo objeto, e se constitui em uma referência no âmbito local, graças ao domínio técnico e conceitual que adquiriu. Ao mesmo tempo, esse pesquisador opera como um provedor de dados para o laboratório "central" que o acolheu (junto com outros colegas de países em desenvolvimento). O grupo central exerce o controle cognitivo do tema em questão e, um aspecto importante, o controle econômico das aplicações possíveis dos conhecimentos produzidos. Nessa dinâmica, evidencia-se uma tensão: a visibilidade e a qualidade científica da pesquisa local, legitimadas pelos grupos internacionais, podem entrar em contradição com a aplicação - real e potencial - das pesquisas (4).

Nesse contexto, os líderes locais de cada área veem a si mesmos - e operam - como verdadeiros "intermediários" entre a ciência "universal" e as pesquisas locais. São eles que têm capacidade de estabelecer os vínculos duradouros com os líderes internacionais, nos locais para onde enviam seus estudantes para fazerem os pós-doutorados, com quem participam de projetos em comum etc. Essa estratégia Ihes permite construir a ilusão de uma integração internacional que oculta o caráter subordinado e as duras negociações que estão obrigados a empreender com o fim de serem aceitos no "clube mundial". Na mesma operação, o reconhecimento externo Ihes permite acrescentar seu prestígio local, quer dizer, a consolidação da posição local é obtida na maior parte das vezes de um modo exógeno.

\section{A "NOVA DIVISÃO INTERNACIONAL DO TRABALHO CIENTÍFICO" (NDITC) E A "MEGA-CIÊNCIA" Vários elementos modificam-se} na dinâmica das ciências e da internacionalização ocorrida na América Latina a partir dos anos noventa do século XX, com diferenças radicais em relação aos modelos analisados previamente. Essas mudanças obedecem a razões diversas, que vamos mencionar de modo sucinto:

- Em primeiro lugar, uma mudança das políticas de C\&T dos países desenvolvidos, que se caracteriza por um importante aumento e concentração dos recursos, cujo objetivo é o de gerar "grandes blocos de conhecimento", tal como o "Espaço Europeu de Pesquisa".

- Em segundo lugar, a massificação das comunicações estabelecidas por meios eletrônicos parece ter reforçado a intensidade das colaborações entre os pesquisadores. Essa modalidade de colaboração cria a ficção de uma autonomização com respeito aos contextos específicos nos quais estão implantados. Isso parece incorporar um elemento de "democratização" das relações que regem 


\section{Artigos \& Ensaios}

a produção de conhecimentos, no âmbito de vínculos "universalizados".

- Finalmente, é a própria natureza da pesquisa que se modifica, na medida em que é orientada para abordar questões mais complexas, aumentando proporcionalmente o número de pesquisadores envolvidos em um mesmo projeto. Uma consequência disso é, por exemplo, a "inflação" de assinaturas de artigos científicos, como demonstra, entre outros, Pontille (5) em um texto recente.

Com relação às políticas europeias, embora o discurso favoreça a "ideologia da cooperação internacional", torna-se evidente que os instrumentos postos em prática respondem a uma estratégia de concorrência com a hegemonia norte-americana nos diversos campos do conhecimento. Por parte dos Estados Unidos, encontra-se um discurso ainda mais explícito: "As rápidas mudanças que ocorreram no nível internacional confirmam a necessidade urgente de compreender e controlar o lugar da nossa nação, sua competitividade, as tendências relacionadas especialmente a essa competitividade em altas tecnologias, e a informação crítica que deve gerar para melhor orientar o Estado e a nação em relação ao futuro". E também: "A pesquisa básica, uma vez publicada, pode ser utilizada livremente por todas as nações, e seus resultados beneficiarão não somente as indústrias ou os países que financiaram a pesquisa. Mas as vantagens das indústrias e nações que chegam às descobertas em primeiro lugar são enormes" (6).

Nos últimos anos estabeleceu-se uma competição em termos globais entre a Europa e os Estados Unidos, relacionada com a predominância no desenvolvimento de capacidades de pesquisa científica e inovação. Assim, a União Europeia lançou uma série de iniciativas de financiamento muito diferentes das que havia realizado até então, em comparação com a enorme massa de recursos destinados pelos Estados Unidos a P\&D. Por exemplo, os recentes Programas Marco da União Europeia foram deixando parcialmente de lado as chamadas de projetos - destinados aos grupos científicos de maior prestígio nos países europeus - e, em troca, elaborou-se nos países desenvolvidos um conjunto de iniciativas que tendem à concentração de recursos destinados a um número limitado de redes muito específicas. Estas são constituídas por instituições europeias, mas, e isto é crucial, a participação de equipes de pesquisa em países em desenvolvimento é fortemente encorajada. A importância dos fundos concedidos multiplicou-se significativamente (cada rede conta, desde alguns anos, com recursos inimagináveis tempos atrás). A participação das empresas no financiamento de projetos de P\&D também tem sido estimulada, um ponto sobre o qual os países europeus sempre tiveram certa fraqueza em relação aos Estados Unidos e Japão - com a exceção parcial, para determinados setores de pesquisa, de Alemanha, Reino Unido e Holanda.

Além das mudanças de política, de mecanismos e da dimensão dos financiamentos da $P \& D$, a escala da investigação modificou-se substancialmente: se nos anos posteriores à Segunda Guerra falava-se da big science, nos últimos anos estamos diante do desenvolvimento de uma espécie de "mega science", com redes que podem chegar a reunir mais de 500 pesquisadores (7).

A participação ativa dos países em desenvolvimento nessas redes de grupos e pesquisadores, longe de ser limitada, tem sido fortemente incentivada, inclusive nos textos, e sem que deva estar necessariamente associada a equipes europeias. Na prática, porém, aqueles que tomam a iniciativa na formulação, coordenação e proposta de redes de excelência e dos projetos integrados (que são designados como "project leaders") são sempre grupos europeus, embora na maioria das redes se possa observar uma participação ativa de equipes de pesquisa latino-americanas.

\section{CONSEQUÊNCIAS DO NOVO MODELO PARA OS PESQUISADORES LATINO-AMERICANOS Frente ao panorama apresentado, é} pertinente perguntar-se acerca de quais são as consequências da participação de pesquisadores latino-americanos nas "mega redes". É evidente que a modalidade tradicional de "integração subordinada", tal como exposta acima, modificou-se em vários sentidos:

- Uma restrição às margens de negociação das equipes "periféricas", que devem integrar-se em redes muito amplas cujas agendas já tenham sido fortemente estruturada pelas instituições que as financiam e pelos atores públicos e privados envolvidos,

- Um processo de "divisão internacional do trabalho" que atribui às equipes localizadas em países periféricos as atividades com alto conteúdo técnico e altamente especializadas, mas que sejam subsidiárias de problemas científicos e/ou industriais que já tenham sido estabelecidos. Há, de fato, certa deslocalização do trabalho científico, cujo resultado é a transferência para a periferia 


\section{Artigos \& Ensaios}

de atividades científicas muito especializadas e que exigem alta qualidade técnica, mas que em última instância assumem um caráter rotineiro. Em geral, nessas "mega redes" não se pode negociar mais que os termos de uma subcontratação.

Na medida em que existem "problemas científicos já estabelecidos", os pesquisadores periféricos são convidados a participar a posteriori, uma vez que os programas de pesquisa tenham sido concebidos pelos líderes dos grupos hegemônicos. Essa restrição é reforçada quando se trata de projetos científico-industriais já negociados com as empresas que fazem parte do projeto e, geralmente, não há nenhuma possibilidade para os pesquisadores periféricos de fazer valer os seus próprios interesses cognitivos.

- As equipes de pesquisa da periferia que participam das "mega redes" têm a possibilidade de aumentar significativamente seus recursos, seus vínculos de integração, o recrutamento de jovens etc. Suas estadias nos centros de excelência internacional são funcionais às novas dinâmicas; consistem em períodos de aprendizagem de novos métodos e técnicas que se aplicarão em seguida, quando retornarem aos seus países de origem. Mas não pode ser qualquer sujeito (ou objeto) do contrato, uma vez que é necessário ter adquirido um nível de excelência prévio, apreciado pelos pares da comunidade internacional.

Essas três características do novo modelo nos levam a considerar que a tensão mais forte gerada nesse contexto refere-se à relevância local da pesquisa, à sua utilidade social para a comunidade em que se desenvolve, já que essa modalidade deixa uma margem muito estreita para a formulação de problemas sociais e locais, como problemas do conhecimento.

O processo de mudança pode ser analisado em dois níveis. Em nível formal, vemos que na "universalização liberal" o grau de liberdade das equipes locais era maior e a justificação das agendas de pesquisa locais relacionadas com as necessidades sociais ou econômicas estava em tensão com os vínculos internacionais dos pesquisadores, mas ambas as abordagens não apareciam como excludentes. Os pesquisadores locais pretendiam produzir conhecimentos "de excelência", e suas pesquisas estavam justificadas como parte do "progresso geral do conhecimento" e seus usos potenciais. Entretanto, esse modelo teve mais consequências simbólicas que materiais: a maior parte do conhecimento produzido serviu mais para aumentar a visibilidade dos pesquisadores locais que para gerar conhecimentos localmente úteis e apropriáveis.

Certamente, definir as necessidades sociais que podem ser objeto de "demanda de conhecimentos" é um problema complexo, na medida em que supõe interrogar-se sobre os atores que têm a legitimidade e a capacidade para formular tais demandas. Isso implica na determinação dos mecanismos pelos quais os "problemas sociais" se traduzem em "problemas de conhecimento". No entanto, na etapa atual da mega science e da NDITC, essas margens são praticamente inexistentes, posto que a maior parte dos problemas científicos já foi definida. Por isso, o principal desafio hoje é dar conta dessa forte tensão e gerar ações capazes de redirecionar os esforços locais de produção de conhecimentos.

Pablo Kreimer é pesquisador do Conicet (Consejo Nacional de Investigaciones Científicas y Técnicas de La República Argentina) e professor titular de sociologia da ciência das Universidades de Quilmes e Mar del Plata (Argentina).

Tradução: Flávia Gouveia

\section{NOTAS E REFERÊNCIAS BIBLIOGRÁFICAS}

1. "Liberal" é entendido aqui no sentido de práticas que não são reguladas pelas autoridades nacionais nem pela direção das instituições. Trata-se, ao contrário, de práticas marcadas por um laissez-faire que não responde mais do que às estratégias dos próprios pesquisadores.

2. A expressão "liberal orientada" poderia parecer contraditória. Refiro-me, entretanto, à implementação de mecanismos de ajuda à cooperação internacional que não afetaram, porém, a liberdade dos pesquisadores para estabelecer livremente seus vínculos internacionais.

3. Kreimer, P., “¿Dependientes o integrados? La ciencia latinoamericana y la división internacional del trabajo." Nomadas-CLACSO, nº 24. 2006.

4. Para um desenvolvimento dessa ideia, veja-se Kreimer (2009). A situação foi observada com agudeza, pela primeira vez, por Varsavsky (1969).

5. Pontille, D., Écologies de la signature en science. Sociétés \& Représentations, $\mathrm{n}^{\circ} 25$, p. 137-156 (numéro spécial «Ce que signer veut dire»). 2008.

6. National Science Foundation, Research and development: essential Foundation for U.S. Competitiveness in a global economy. Washington, NSF. 2008.

7. Um exemplo global foi o projeto "Genoma Humano" e outro, mais recente, chamado "Máquina de Dios".

\section{BIBLIOGRAFIA CONSULTADA}

Kreimer, P., "El científico es también un ser humano. La ciencia bajo la lupa. Buenos Aires, siglo XXI." 2009.

Varsavsky, O., Ciência, politica, cientificismo. Buenos Aires, Centro Editor de América Latina.1969. 